\title{
Sobre o Poder: Religião e Política
}

\author{
Profa. Dra. Neusa Romero Barazal
}

\section{RESUMO}

As sociedades humanas funcionam através de padrões culturais próprios que têm normas, regras, leis, convenções, ações, ou seja, um conjunto de valores materiais e espirituais que pretendem manter o equilíbrio e o funcionamento das mesmas. Para tanto, são estabelecidas relações de Poder capazes de transformar possibilidades em atitudes comportamentais dos agentes sociais. Dentre os exemplos, pode-se citar a Religião com a função de estabelecer o sentido da vida, do sofrimento, da morte, da esperança no futuro. Trata-se de uma instituição poderosa e duradoura. Outro exemplo é o da Política manifesta por intermédio do Estado moderno e laico que detém os atos de ordenação e proibição de um determinado grupo social, em determinado território, assim como, sua defesa e sua derrubada. No entanto, na dialética entre as concepções religiosas e o racionalismo do Estado moderno, observa-se o caso das eleições de 2018 no Brasil.

Palavras-chave: Cultura; Poder; Religião; Política; Eleição

\section{ON POWER: RELIGION AND POLITICS}

\section{ABSTRACT}

Within their own cultural patterns, human societies have norms, rules, laws, conventions, and actions in which are operated as a set of material and spiritual values aiming balance power functioning. For that, Power relations are established, capable of transforming possibilities into of social agents' behavioral attitudes. Among the examples, one can mention Religion regarding the establishing function of life meaning, suffering,

* Doutora em Ciências Sociais - Relações Internacionais, pela Pontifícia Universidade Católica de São Paulo. Mestre em Integração da América Latina, pela USP - PROLAM - Programa Integração América Latina. Professora no Centro universitário Fundação Santo André. 
death or future hope. It is a powerful and lasting institution. Another example is Politics as manifested through a modern and secular State that holds the acts of ordering and prohibiting a particular social group in a given territory, as well as its defense and overthrow. However, in the dialectic between religious conceptions and rationalism of the modern State, the 2018 elections in Brazil is observed.

Keywords: Culture; Power; Religion; Politics; Election.

Nenhuma sociedade humana, nenhum povo, nenhuma comunidade jamais agirá de forma idêntica aos demais. Poderá haver semelhanças. Isto tem a ver com os padrões de conduta ou padrões culturais que compreendem normas, regras, leis, convenções, ações e um conjunto de valores materiais e espirituais que os indivíduos assimilam com o objetivo de manter o equilíbrio e o funcionamento normal das sociedades.

Vale dizer que esses fenômenos culturais se encontram em um processo de transformação constante e, sem eles, o homem estaria impossibilitado de criar sua sociedade. Sua personalidade e suas características pessoais serão moldadas pelas normas, padrões de conduta do seu meio social. Portanto, a Cultura funciona como um sistema de comunicação cujo código precisa ser compreendido pelos indivíduos que dela participam. Daí a sua importância no entendimento da vida social.

Nesse sistema de comunicação da vida social humana a Fé no Sagrado é uma manifestação universal, constata-se a não existência de sociedade sem Religião. Encontra-se desde o passado até hoje os estados religiosos que se traduzem em atitudes, atos e hábitos de espírito que foram sendo adquiridos pelos indivíduos no transcurso dos séculos, tornando-se hereditários e coletivos. Segundo Bergson (1978), a Religião obedece a instintos virtuais e reais relacionados às exigências fundamentais da vida que se transformam em consciência moral. No entanto, nenhuma definição singular ou simples bastará para definir o termo: Religião. Isso porque, "as definições dos dicionários (como, por exemplo, "o reconhecimento humano do poder sobrenatural", "a crença em Deus", "qualquer sistema de fé e de culto") são frequentemente perifrásticas, preconceituosas ou tão genéricas que se tornam inúteis" (HINNELS, 1984: p.217). 
Aqueles que definem o termo Religião estão sujeitos ao erro porque a real constatação da universalidade do fenômeno religião não permite que lhe seja atribuída um significado totalizante e universal que compreenda todas as suas manifestações particulares e singulares. Daí a proposição de alguns estudiosos sobre o emprego de nomes próprios para as chamadas religiões seja substituído pela terminologia "a religião de" (um povo ou uma área cultural). O fenômeno totalizante e universal é o da existência da Fé no Sagrado.

De modo abrangente, pode-se dizer que a função exercida pela Religião diz respeito a questões de significação como, o sentido da vida, do sofrimento e da morte, assim como dos meios adequados para se manter a esperança num futuro melhor que são adotadas em diferentes culturas, estando diferente em sensibilidades e interpretações dos indivíduos. Não são menores as variações nas formas sociais dos significados ao longo dos períodos de tempo. Tudo isso ajudou a "estabelecer a religião como instituição poderosa e duradoura em virtualmente todas as sociedades conhecidas, embora não seja necessário que os indivíduos a compreendam e aceitem. Em outras palavras, a religião é uma qualidade potencial da experiência humana para a qual nenhum limite pode ser fixado por definição" (OUTHWAITE et al. 1993: p.659).

Como qualidade da experiência humana, outra função da Religião que se observa ao longo da história, diz respeito à utilização de preceitos sagrados como base para o ordenamento político. Nesse caso, o Poder que é exercido pelo homem acontece sob a forte influência da autoridade divina representada na Terra. Em muitos exemplos, a legitimidade dessa autoridade divina é entendida através de uma encarnação humana. Em outros, há o reconhecimento de uma hierarquia sacerdotal que interfere na vida sagrada e profana de toda a sociedade. Em ambos os exemplos, observa-se a subordinação do laico ao sagrado gerando o "governo de Deus" ou a teocracia que devido a um mandato divino, assume a tarefa de prover o bem-estar do povo.

São muitas as situações históricas que apresentaram e apresentam regimes teocráticos na organização política de diferentes povos. São registrados casos como "o Tibete do Dalai Lama, o Japão Imperial, o Egito faraônico, e em termos bastante conspícuos a organização política do povo hebreu durante o período sacerdotal [...], o Ocidente entre 
o final do Século XI e o início do Século XIV, por obra do papado" (BOBBIO; MATTEUCCI; PAQUINO, 1995: p. 1237).

A título de ilustração Santo Agostinho, em sua obra De Civitate Dei, defende a ideia de uma subordinação necessária do Estado à Igreja. A observação da implantação dessas ideias no período medieval mostrou que ao Estado era vedada toda interferência em matéria eclesial e, à Igreja, não era interditada a ingerência no campo temporal. Tudo isso porque se partiu da premissa de que o poder espiritual é superior a todo o poder terreno, e, quando há erros terrenos, eles serão julgados pelo poder espiritual. Mais adiante, historicamente falando,

a reforma protestante, ao romper a unidade religiosa europeia, marca o ocaso definitivo do sistema teocrático [e] com base nesta teoria, a Igreja conserva o poder de julgar e condenar a atividade do Estado e dos soberanos todas as vezes em que a mesma puser de qualquer maneira em perigo a salvação das almas (BOBBIO; MATTEUCCI; PAQUINO, 1995: p. 1238).

Com o surgimento das concepções modernas a respeito da autonomia entre Religião e Política, foi sendo adotado o conceito de laicismo que passará a distinguir Estado de Igreja e será defendido por vários pensadores da época como John Milton e John Locke que em sua obra Tratado sobre a Tolerância, defende que o Estado não tem poder em matéria espiritual enquanto que a Igreja não tem poder em matéria temporal. Em outras palavras, não cabe ao primeiro emitir juízos a respeito de religião e fé, e a Igreja deve restringir sua autoridade ao campo espiritual.

Desse modo, o racionalismo moderno passará a submeter às verdades definitivas o controle permanente da razão e, conseguintemente, ter-se-á a exclusão da verdade absoluta (sagrada) no seu radar de entendimento da verdade. Portanto, a adoção do espírito leigo moderno produzirá um democratismo agnóstico onde o Estado, manifestação do interesse nacional, terá por dever permitir a Religião como manifestação de fé de seu povo e de favorecer o culto religioso. A liberdade de manifestação religiosa passará a conviver com a liberdade de crítica às Religiões. 
A maioria dos Estados modernos passará a reivindicar a laicidade como princípio norteador de sua constituição, apoiada pela Declaração Universal dos Direitos Humanos, promulgada em 1948 pela Organização das Nações Unidas - ONU reconhecendo o direito à liberdade de religião, de crença, de práticas, de culto, de observação dos ritos de forma privada ou pública, particular ou em comunidade.

Voltando ao conceito de Cultura como sendo o sistema de comunicação da vida social humana, o Poder é uma manifestação universal ao constatar-se a não existência de sociedade sem o Poder. Ao considerar o Poder em seu sentido especificamente social pode-se observar um leque de manifestações que vão desde a capacidade de agir com poder; do poder do homem sobre o homem; do homem ser sujeito e objeto do poder social; do Governo estabelecer ordens aos cidadãos; do poder do homem sobre a natureza e da utilização de seus recursos; e outras formas manifestas de Poder terreno. Resumidamente pode-se dizer que há o Poder sobre homens, sobre a natureza e sobre as coisas que se relacionam entre si.

Além do mais, o exercício do Poder tem a capacidade de determinar o comportamento dos envolvidos quando se transforma em atitudes, passando de possibilidades à ação. Pode-se dizer que não existe relação social onde o Poder não se faça presente influenciando indivíduos ou grupos de indivíduos como, por exemplo, pequenos grupos de produção, de famílias, de classes sociais, etc. Desse modo, o conceito de Poder serve para interpretar diferentes aspectos da sociedade, mas o seu papel mais destacado acontece na Política. A Política entendida como forma de atividade que está estreitamente ligada ao Poder, é uma atividade geral do ser humano, isto é, está em toda a sua história. Assim compreendida, não se deve confundi-la com o Estado, que é apenas uma de suas manifestações históricas.

A Política em seu significado clássico e moderno deriva de polis que representa tudo que se refere à cidade, urbano, civil, público, sociável. Cabendo aqui a explicação de que a Política se expandiu graças à influência da obra de Aristóteles, intitulada Política que é considerada como o primeiro tratado sobre a natureza, a função e as divisões do Estado. Nas palavras de Aristóteles tem-se que 
o homem é, por sua natureza, como dissemos desde o começo ao falarmos do governo doméstico e do dos escravos, um animal feito para a sociedade civil. Assim, mesmo que não tivéssemos necessidade uns dos outros, não deixaríamos de desejar viver juntos. Na verdade, o interesse comum também nos une, pois cada um aí encontra meios de viver melhor. Eis, portanto, o nosso fim principal, comum a todos e a cada um em particular. Reunimo-nos, mesmo que seja só para pôr a vida em segurança. A própria vida é uma espécie de dever para aqueles a quem a natureza a deu e, quando não é excessivamente cumulada de misérias, é um motivo suficiente para permanecer em sociedade. Ela conserva ainda os encantos e a doçura neste estado de sofrimento, e quantos males não suportou para prolongá-la! (ARISTÓTELES, 1998: p. 53).

Dessa forma, cabem à esfera da Política os atos de ordenação e proibição de alguma coisa com efeitos vinculadores a todos os membros de um determinado grupo social, sobre um determinado território como a conquista, a manutenção, a defesa, a derrubada do poder estabelecido.

Para Max Weber, as relações de mando e de obediência, mais ou menos confirmadas no tempo, e que se encontram tipicamente na política, tendem a se basear não só em fundamentos materiais ou no mero hábito de obediência dos súditos, mas também e principalmente num específico fundamento de legitimidade. Deste Poder legítimo, que é muitas vezes designado pela palavra Autoridade, Weber especificou três tipos puros: o Poder legal, o Poder tradicional e o Poder carismático. O Poder legal, que é característico da sociedade moderna, funda-se sobre a crença na legitimidade de ordenamentos jurídicos que definem expressamente a função do detentor do Poder. [...] O Poder tradicional funda-se sobre a crença no caráter sacro do Poder existente "desde sempre". [...] O Poder carismático, enfim, está fundado na dedicação efetiva à pessoa do chefe e ao caráter sacro, à força heroica, ao valor exemplar ou ao Poder de espírito e da palavra que o distinguem de modo especial. A fonte do poder se conecta com o que é novo, com o que não existiu nunca, e por isso o Poder tende a não suportar vínculos predeterminados. Quem comanda verdadeiramente é o líder e aqueles que prestam obediência são os discípulos (BOBBIO; MATTEUCCI; PAQUINO, 1995: p. 940). 
Max Weber concebe as relações de Poder enfatizando a importância da legitimidade daqueles que detêm a Autoridade sobre os seus súditos. Não existe continuidade da Política se ela não tiver seus alicerces de comando e de obediência, reciprocamente, sem o elemento de legitimação que é a Lei (burocracia), a Tradição (patriarcado) ou o Carisma (espírito e palavra ou graça pessoal) daquele que governa. Para Weber (1997), como todas as associações políticas que historicamente precederam o Estado moderno, verifica-se uma relação de dominação de homens sobre homens, que se sustentam por meio da violência legítima. Para sua subsistência necessita que os dominados acatem a autoridade que pretendem ter aqueles que no momento dominam.

Nesse sentido, a legitimidade da autoridade exercida pelo governante serve para sustentar o Estado moderno (que corresponde ao movimento de racionalização da civilização moderna), definido por uma associação política que detêm a violência no sentido de todo Estado estar fundado no exercício de uma violência legitimada pelo direito.

Ao voltar-se a atenção para o Estado moderno, cuja estruturação se dá através do direito, onde se dá a passagem da legitimidade para a esfera da legalidade, tem-se como discurso a adoção da liberdade política, a igualdade de participação dos cidadãos frente ao poder. $\mathrm{O}$ ordenamento jurídico do Estado moderno respeita o indivíduo e seus direitos naturais, sobretudo no campo da economia, frente ao Estado absoluto de até então. Dá-se a constituição do Estado moderno como Estado social que se faz através de seu aparelho e de sua função de gestão da ordem social. Sua operacionalização acontece,

de um lado, comportando uma racionalização do direito com as consequências que são a especificidade do poder legislativo e judiciário, bem como a instituição de uma polícia encarregada de proteger a segurança dos indivíduos e de assegurar a ordem pública; de outro lado, apoia-se em uma administração racional, baseada em regulamentos explícitos, que lhe permitem intervir nos domínios mais diversos, desde a educação até a saúde, a economia e mesmo a cultura; enfim dispõe de uma força militar por assim dizer permanente" (FREUND, 1966: p.159).

Naturalmente, surgem críticas aos postulados racionalistas na elaboração do direito moderno quando se evidencia que a realidade física 
não é totalmente conforme ao que se considera ser racional e quando a não-racionalidade da realidade (ou uma parte dela) tem de ser reconhecida, como transferi-la para o texto legal? Na estruturação legal do Estado moderno é condição indispensável que se aceite a maneira como o Direito se revela estabelecido pelo sistema político vigente. No entanto, isso pode não corresponder com as ideias grandiosas sobre a Liberdade, a Justiça, a Democracia e outros temas caros que são reproduzidas pela razão humana. Portanto, a construção de um Estado moderno e laico representa um grande desafio quando se depara com as concepções meramente racionalistas, de um lado, e as concepções morais e religiosas, de outro. Esse é o desafio da síntese a ser desenvolvida pelo homem e sua sociedade plural e inclusiva. Voltando a Pascal,

uma revelação divina tem de ser aceita (ou rejeitada), mas não pode ser posta em dúvida só porque não é racional. Da mesma maneira, em ciência, os fatos têm de ser aceitos, estejam ou não em conformidade com as expectativas da razão. Portanto, a despeito de sua estrita distinção metodológica entre ciência e teologia, o método científico de Pascal traz a marca de sua fé religiosa [...] Pascal não era irracionalista, pois considerava a razão como o dom mais sublime do homem - "toda a nossa dignidade reside no pensamento" (HOOYKAAS, 1998: p.69).

Como Pascal, muitos protagonistas modernos estabeleceram o paralelo entre suas concepções religiosas e o racionalismo científico ou moderno, método adotado pela maioria dos Estados modernos e laicos. Daí que a operacionalização da moralidade e da racionalidade na sociedade moderna produz códigos de conduta em constante construção.

Trazendo a discussão teórica para uma situação concreta, pode-se pensar o momento político vivido no Brasil durante o processo eleitoral de 2018, notando-se que a vitória de Jair Bolsonaro, que assumirá a Presidência da República em janeiro de 2019, se deu como um fenômeno que a muitos surpreendeu frente ao status quo político que se consolidou no País desde 30 anos. A Constituição da República Federativa do Brasil, que evidencia o Estado laico, completou 30 anos em 2018.

No entanto, nos últimos anos tem-se percebido a corrosão de Instituições abaladas pela corrupção. As descobertas e denúncias não deixaram de se reproduzir dia-a-dia envolvendo os mais diversos cargos 
políticos da República. Como consequência, o processo de deterioração da realidade brasileira nos mais diversos campos da vida que vão desde saúde, educação, segurança. A descrença de que crimes de "colarinho branco" pudessem ser punidos exemplarmente levaram a população a um estado de desânimo generalizado.

Com a instalação da Operação Lava Jato, o Ministério Público, a Polícia Federal e o Judiciário devolveram um pouco de alento para uma população em crise pela quebra dos códigos de conduta de muitos dos políticos corruptos ao verificar que, alguns deles foram sentenciados e presos. No entanto, os meios de comunicação continuaram apresentando denúncias de malfeitos diários passando a sensação de que as punições não estavam atingindo seus objetivos de intimidação aos demais corruptos que continuaram e continuam delinquindo.

A partir daí, instala-se a crise política, social, econômica e ética que atinge de forma generalizada a população brasileira gerando o sentimento de autodefesa de uma grande parcela de pessoas que, defensoras e preocupadas com o espírito do dever que é responsável pela alma da cultura, decidisse valorizar a ideia da obrigação moral consigo e com os demais. A vontade de conciliação entre os valores e os interesses, entre o princípio dos direitos dos indivíduos e os contratos da vida social serviram como contraponto ao estado de coisas que ocorrem atualmente no Brasil. Boa parte dessa população encontrava-se muda e atônita diante dos acontecimentos sem um espaço comum de manifestação de seus sentimentos. O movimento de 2013 que levou muitos brasileiros às ruas para manifestar seu descontentamento com a conjuntura brasileira serve aqui de exemplo. Curiosamente, muitos analistas ficaram sem saber o que havia acontecido ou motivado ou promovido tal fato por conta da espontaneidade e da falta de uma liderança para um movimento de dimensões nacionais. O sentimento de descontentamento fez "emergir o monstro da lagoa" que voltou a silenciar apesar dos apelos feitos por diversos movimentos organizados e instituídos com intuito de cooptar o movimento caracteristicamente espontâneo. Foi em vão.

A crise de representação política e a falta de perspectiva no futuro depararam com a racionalidade técnica e positivista da cibernética que através das redes sociais permitiu um novo processo de comunicação que, virtualmente e informalmente, produziu a aproximação e a iden- 
tificação dessa massa de gente que encontrou o espaço para a sua manifestação, fora dos demais meios de comunicação tradicionais, sem se fazer perceber ou sendo ignorados por aqueles que estavam fora dessa grande "bolha de insatisfeitos reunidos".

A "bolha" encontra e identifica em seu espaço virtual o fenômeno da indignação com os últimos acontecimentos e, ao mesmo tempo, o transforma no discurso anti-situação, anti-sistema propondo a retomada do Brasil pela recuperação da fé no futuro. Nesse contexto, constrói-se um discurso da responsabilidade humana frente ao trabalho de fazer face aos desafios da consciência, da unidade para a superação dessa fase que exige autocontrole, retificação e inovação conjunta para a manutenção da democracia, porém, suplementada pela moral dos costumes brasileiros. Diante de tamanho desafio e frente a tantos discursos desencontrados, foi aquele que aproxima a política à religião que ganha eco junto à boa parte desses cidadãos brasileiros.

Com esse objetivo os brasileiros escolheram o caminho alternativo das urnas que se expressou no slogan "Brasil acima de tudo, Deus acima de todos". Em outras palavras, o Brasil, um Estado moderno de direito e laico que está acima de tudo, devendo ser respeitado enquanto tal, sendo tutelado por Deus que é colocado hierarquicamente acima de todos indiscriminadamente.

\section{REFERÊNCIAS}

ARISTÓTELES. A Política. 2 ed. São Paulo. Livraria Martins Fontes. 1998. BERGSON, Henri. As duas fontes da Moral e da Religião. Rio de Janeiro. Zahar Editores. 1978.

BOBBIO, Norberto; MATTEUCCI, Nicola; PASQUINO, Gianfranco. Dicionário de Política. V2. 8ed. Brasília. Editora Universidade de Brasília. 1995. FREUND, Max. Sociologia de Max Weber. Rio de Janeiro. Editora Forense Universitária. 1987.

HINNELLS, John R. Dicionário das Religiões. São Paulo. Círculo do Livro. 1984. HOOYKAAS, R. A Religião e o Desenvolvimento da Ciência Moderna. Brasília. Editora Universidade de Brasília. 1988.

OUThWAite, Willian et al. Dicionário do Pensamento Social do Século XX. Rio de Janeiro. Jorge Zahar Editor. 1993. 